\title{
PENERAPAN PROMOSI DAN STRATEGI PEMASARAN TERHADAP PERKEMBANGAN USAHA (PT JM MUTU UTAMA SERPONG)
}

\author{
Masran Mustakim \\ email :dosen01037@gmail.com
}

\begin{abstract}
ABSTRAK
Strategi pemasaran merupakan cara yang sangat penting untuk diterapkan oleh perusahaan jasa maupun non jasa agar dapat bersaing di pasar. Penelitian ini bertujuan : (1) Untuk mengetahui strategi pemasaran yang digunakan oleh PT JM Mutu Utama dalam meningkatkan volume penjualan. (2) Untuk menganalisa strategi pemasaran yang seharusnya dilakukan oleh PT JM Mutu Utama yang sesuai dengan kondisi perusahaan saat ini.

Penelitian ini dilakukan di PT JM Mutu Utama dengan menggunakan metode penelitian deskriptif dengan melakukan observasi. Metode pengumpulan data yang digunakan adalah metode penelitian lapangan dan kepustakaan. Untuk menganalisis data dari lapangan, digunakan metode deskriptif dengan menggunakan analisis SWOT (Streght, Weakness, Opportunity, Threat).

Hasil penelitian menunjukan bahwa (1) Strategi penerapan prromosi yang dilakukan oleh PT JM Mutu Utama mampu meningkatkan pertumbuhan volume penjualan. (2) Melalui analisa EFAS (External Strategic Factor Analysis Summary) diperoleh skor total 2,70 dan melalui analisa IFAS (Internal Strategic Factor Analysis Summary) diperoleh skor total 3,45. Sehingga nilai tersebut dimasukan pada analisa SWOT yang menunjukan posisi PT JM Mutu Utama berada pada kuadran I, sehingga strategi pemasaran yang cocok dilakukan oleh PT JM Mutu Utama adalah Strategi Agresif atau perluasan untuk memaksimalkan kekuatan internal dan eksternal perusahaan dengan melakukan pengembangan pasar, pengembagan produk, dan inovasi.

Saran yang diberikan peneliti kepada PT JM Mutu Utama adalah dengan mengetahui hasil dari penelitian strategi pemasaran perusahan maka diharapkan agar PT JM Mutu Utama lebih memperhatikan sumber daya manusia, anggaran promosi, dan menjalin kemitraan dengan perusahaan lain.
\end{abstract}

Kata Kunci : Strategi Pemasaran 


\begin{abstract}
Marketing strategy is an important way to be applied y service and non-service company in order to be able to compete in market. The aims of this research are (1) To know the marketing strategy which was used by PT JM Mutu Utama (2) To analyze the marketing strategy which should be used by PT JM Mutu Utama which suitable with the condition of the company.

This research is conducted in PT JM Mutu Utama which uses descriptive method by using observation. The collecting data methods which are used in this research are field research and library research. To analyze the data which are got from the field, it uses descriptive method by using Analysis SWOT (Streght, Weakness, Opportunity, Threat).

The result of research show that (1) Marketing Mix Strategy that is used by PT JM Mutu Utama can increase the growth of selling volume (2) Through EFAS analysis (External Strategic Factor Analysis Summary) is gained 2,70 total score and through IFAS analysis (Internal Strategic Factor Analysis Summary) is gained 3,45 total score. Therefore, those scores are set on SWOT analysis which shows are the position of PT JM Mutu Utama in the first quadrant the suitable strategy is aggressive an expansion strategies, by maximing internal and external streght of the company, so it is possible to expanse the market enlarge the product and innovation.

The research suggests to PT JM Mutu Utama by knowing the result of this research in company marketing strategy, is hoped that PT JM Mutu Utama give more attention to human resources, the promotion budget, and makes the good relationship with other companies.
\end{abstract}

Keyword : Marketing Strategy 
Manajemen Pemasaran ISSN No. (PRINT) 2598-0823, (ONLINE) 2598-2893

\section{A. Pendahuluan}

Berikut ini bauran pemasaran yang dilakukan oleh PT JM Mutu Utama

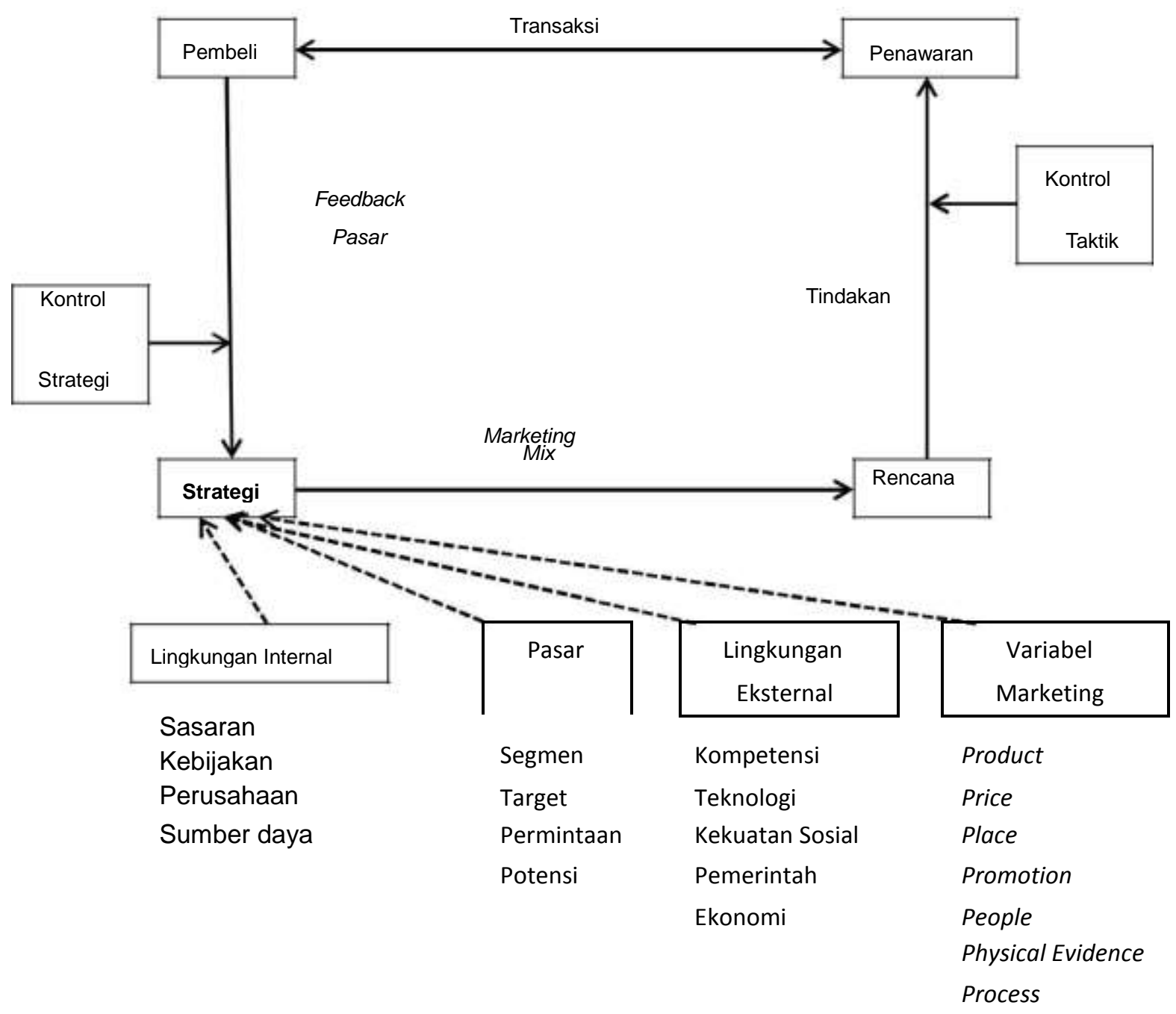

Gambar : Hubungan Variabel Marketing Mix dengan Variabel lain

Seperti dideskripsikan oleh garis putus - putus, variable-variable marketing berfungsi sebagai pertimbangan -pertimbangan dalam menemukan dan memilih strategi yang digunakan. Campuran dari variable-variable ini dalam program pemasaran akan menjadi sangat efektif dalam mengaplikasikan strategi. Keputusan - keputusan kemudian sampai pada marketing mix sebagai pokok kajian dalam analisa ini. 


\section{PRODUK}

Semua produk yang dijual oleh PT JM Mutu Utama telah terdaftar legal sebagai persyaratan standar internasional system manajemen kualitas (Quality Management System - Requirments) dengan nomor registrasi AS/NZS ISO 9001:2000 yang dikeluarkan oleh SAI Global Limited dan IQNet (The International Certification Network atau Jaringan Sertifikasi Internasional). Persyaratan ini menunjukan kemampuan dalam bidang design, produksi, dan pemasaran produk kimia spesialisation dalam aplikasi - aplikasi industry kimia dan areal produksi minyak. Dengan adanya sertifikasi tersebut mengindikasikan bahwa standar kualitas produk - produk kimia, termasuk speciality chemicals dari PT JM Mutu Utama yang telah diakui secara internasional.

\section{HARGA}

Untuk sejumlah alasan, Divisi pemasaran PT JM Mutu Utama menilai variable harga sebagai signifikan strategis yang unik. Tidak hanya karena variable harga merupakan pertimbangan penting dalam menyesuaikan sumber daya dan suplai kepada permintaan user sehingga tercapai profit , harga dapat menjadi kekuatan besar dalam menarik atensi dan meningkatkan penjualan. Berbeda dengan produk, promosi, dan distribusi. Harga dapat diatur dengan cepat dan sering untuk menyesuaikan fluktuasi supply and demand.

\section{PROMOSI}

Keputusan - Keputusan promosi dari PT JM Mutu Utama sering dibuat secara simultan dengan keputusan - keputusan bauran pemasaran lainnya. Terkait dengan pengembangan strategi promosi, putusan - putusan tersebut mencakup penemuan pasar - pasar dan audiens targer, penentuan sasaran - sasaran dan tugas-tugas anggaran promosi dan mengontrol elemen elemen promosi, dan lain - lain.

Dari latar belakang masalah diatas, dimana aspek strategi pemasaran berperan vital dalam beberapa kasus secara signifikan menentukan kemajuan dan atau kebangkrutan dunia usaha. Pada kesempatan ini Penulis tertarik untuk 
membahas mengenai pengaruh penerapan strategi pemasaran terhadap perkembangan usaha pada PT JM Mutu Utama.

\section{B. Perumusan Masalah}

Didasarkan pada latar belakang masalah, maka perumusan masalahannya adalah sebagai berikut :

1. Apakah strategi pemasaran yang digunakan oleh PT JM Mutu Utamauntuk meningkatkan volume penjualan?

2. Bagaimana strategi pemasaran yang seharusnya dilakukan oleh PT JM Mutuutama supaya sesuai dengan kondisi perusahaan saat ini?

\section{Tujuan Penelitian}

Hal ini bertujuan untuk :

1. Untuk mengetahui strategi pemasaran yang digunakan oleh PT JM Mutu Utama dalam meningkatkan volumepenjualan.

2. Untuk menganalisa strategi pemasaran yang seharusnya dilakukan oleh PT JMMutu utama supaya sesuai dengan kondisi perusahaan saatini.

\section{Landasan Teori}

\section{Pengertian Pemasaran Menurut Definisi ParaAhli:}

1. Menurut Kotler (2004:7), "Pemasaran adalah suatu proses sosial dan manajerial yang didalam individu dan kelompok mendapatkan apa yang mereka butuhkan dan inginkan dengan menciptakan, menawarkan, dan mempertukarkan produk yang bernilai dengan pihaklain."

2. Menurut Carl Mc Daniel dan Roger Gotes (2001:4), "Pemasaran adalah proses merencanakan dan melaksanakan konsep, memberi harga, melakukan promosi, dan mendistribusikan ide, barang atau jasa untuk menciptakan pertukaran yang memenuhi tujuan individu dan organisasi."

Dari definisi - definisi diatas, kesimpulannya dari pemasaran adalah suatu system keseluruhan dari kegiatan untuk merencanakan, menentukan harga, mempromosikan dan mendistribusikan barang atau jasa yang memuaskan kebutuhan baik kepada pembeli yang ada maupun pembeli potensial."

Philip Kotler (2001:4) menurunkan beberapa konsep inti pemasaran, antara lain: 


\section{a. Kebutuhan, Keinginan, danPermintaan}

Kebutuhan - Konsep paling pokok yang melandasi pemasaran adalah kebutuhan manusia. Kebutuhan adalah suatu keadaan perasaan yang membutuhkan pemenuhan terhadap sesuatu seperti makanan, pakaian, perumahan, harga diri, rasa aman dan kasih saying. Kebutuhan ini tidak diciptakan oleh masyarakat atau pemasar tetapi sudah ada dan terlekat dalam tubuh dan kondisimanusia.

Keinginan - Konsep pokok kedua dalam pemasaran adalah keinginan manusia, Keinginan yaitu kehendak yang kuat akan pemuasan yang spesifik terhadap kebutuhan - kebutuhan tersebut .

Permintaan - Manusia memiliki kebutuhan dan keinginan yang tidak terbatas, namun sumber dayanya terbatas. Karena itu dengan keterbatasan sumber daya yang ada, mereka memilih produk-produk yang menghasilkan kepuasan maksimal..

\section{b. Produk}

Produk adalah sesuatu yang dapat ditawarkan kepada pasar untuk mendapat perhatian, untuk dimiliki, digunakan, ataupun dikonsumsi dalam rangka memenuhi kebutuhan atau keinginan.

\section{c. Utilitas, Nilai dan Kepuasan}

Tafsiran konsumen mengenai kapasitas keseluruhan suatu produk untuk memuaskan kebutuhan disebut utilitas,

\section{d. Pertukaran}

Pemasaran terjadi apabila orang memutuskan untuk memenuhi kebutuhan dan keinginannya melalui pertukaran. Pertukaran adalah kegiatan untuk memperoleh barang/jasa yang diinginkan dari pihak lain dengan memberikan sesuatu sebagai gantinya.

\section{e. Transaksi danHubungan}

Transaksi mengandaikan adanya nilai-nilai yang dipertukarkan diantara dua pihak. Transaksi melibatkan sedikitnya dua barang atau jasa yang bernilai, syarat-syarat yang disepakati, waktu kesepakatan dan tempat kesepakatan. 


\section{f. Pasar}

Konsep transaksi mengarah pada konsep pasar. Pasar adalah himpunan pembeli nyata dan pembeli potensial atas suatu produk.

\section{g. Pemasar dan CalonPembeli}

Pemasar adalah orang yang mencari satu atau lebih konsumen yang akan terlibat dalam pertukaran nilai. Calon pembeli adalah orang yang mungkin bersedia dan mampu terlibat dalam pertukaran nilai.

\section{h. Organisasi}

Konsep pemasaran juga menyatakan bahwa kunci untuk meraih tujuan organisasi adalah menjadi lebih efektif dari pada para pesaing dalam memadukan kegiatan pemasaran guna menetapkan dan memuaskan kebutuhan pasarsasaran.

Menurut Kotler \& Armstrong (1997:48), "Bauran pemasaran atau marketing mix adalah perangkat alat pemasaran taktis yang dapat dikendalikan, produk, harga, distribusi, dan promosi yang dipadukan oleh perusahaan untuk menghasilkan respons yang diinginkan dalam pasar sasaran".

Unsur - Unsur bauran pemasaran terdiri dari 7P yang digambarkan sebagai berikut :

\section{a. Product (Produk)}

Strategi produk yang dapat dilakukan mencakup keputusan tentang bauran produk (product mix), Merk dagang (brand), cara pengemasan produk (product packaging), tingkat mutu atau kualitas produk dan pelayanan (services).

\section{b. Price(Harga)}

Penetapan harga yang tepat, mampu menjadikan kegiatan pemasaran berjalan dengan baik dan optimal terhadap barang - barang dan jasa yang ditawarkan.

\section{c. Place(Tempat)}

Terdapat 3 (tiga) macam tipe Interaksi antara penyedia barang atau jasa dan pelanggan yang berhubungan dengan pemilihan place, yaitu sebagai berikut 
1. Pelanggan mendatangi penyedia barang ataujasa

2. Penyedia barang atau jasa mendatangipelanggan

3. Penyedia barang atau jasa dan pelanggan melakukan interaksi melaluiperantara.

\section{d. Promotion(Promosi)}

Dalam kampanye promosi, perusahaan dapat menggunakan promotion mix yang meliputi:

1. Personal Selling merupakan komunikasi langsung antara penjual dan calon pelanggan untuk memperkenalkan suatu produk kepada calon pelanggandan membentuk pemahaman terhadap produk sehingga mereka kemudian mencoba untuk membelinya.

2. Mass Selling merupakan pendekatan yang menggunakan media komunikasi untuk menyampaikan informasi kepada khalayak ramai dalam satu waktu, misalnya menggunakan bentuk periklanan, danpublisitas.

3. Promosi Penjualan adalah bentuk persuasi langsung melalui penggunaan berbagai insentif yang dapat diatur untuk merangsang pembelian produk dengan segera dan meningkatkan jumlah barang yang dibelipelanggan.

\section{e. People (Orang)}

Elemen people ini memiliki 2 (dua) aspek yang terdiri dari :

1. ServicePeople

Melalui pelayanan yang baik dan cepat, ramah, teliti, dan akurat dapat menciptakan kepuasaan dan kesetiaan pelanggan terhadap perusahaan yang akhirnya akan meningkatkan nama baik perusahaan.

\section{Customer}

Pelanggan dapat memberikan persepsi kepada nasabah lain tentang kualitas jasa yang pernah didapatnya dari perusahaan.

\section{f. Physical Evidence (Bukti Fisik)}

Bukti fisik adalah suatu hal yang secara nyata turut memengaruhi keputusan konsumen untuk membeli dan menggunakan produk jasa yang ditawarkan.

Bukti fisik dapat dibagi menjadi dua jenis yaitu :

1. BuktifisikEssensial,mewakilikeputusankunciyangdibuatolehpenyediajasa 
mengenai design dan layoutbangunan.

2. Bukti fisik Peripheral, memiliki nilai bila berdirisendiri.

\section{g. Process(Proses)}

Proses adalah dimana barang atau jasa diciptakan dan disampaikan kepada pelanggan dan merupakan hal penting dalam bauran pemasaran, karena pelanggan akan seringkali mempersepsikan system penyampaian barang atau jasa sabagai bagian dari service.

\section{Tujuan Pemasaran}

Menurut Basu Swasta (2002:67) Pemasaran bertujuan memberi kepuasan kepada pembeli dan masyarakat yang lain dalam pertukarannya untuk mendapatkan sejumlah laba atau rasio antara penghasilan dengan pengeluaran yang menguntungkan.

Adapun tujuan yang berorientasi pada manfaat perusahaan adalah sebagai berikut :

1. Keseimbangan penjualan produk tiap segmen pasar yang akan dilayaniperusahaan

2. Mempertahankan atau memperluas pangsapasar

3. Menjaga tingkat penggunaan minimal fasilitasproduksi

4. Mendapatkan dan mempertahankan posisi kepemimpinan pasar (MarketLeadership)

5. Menambah produk - produk baru

6. Memperbaki terus menerus standard kualitas produk

7. Memberikan pelayanan terbaik kepada para pelanggan melalui pemasok barang yang berkualitas baik, tepat waktu dan harga yang wajar

\section{Definisi Manajemen Strategi Menurut Definisi Para Ahli}

Berikut ini adalah beberapa pengertian manajemen strategi dari beberapa ahli:

a. Menurut David (2006:5) Manajemen strategi adalah seni dan pengetahuan dalam merumuskan, mengimplementasikan, serta mengevaluasi keputusan-keputusan lintas fungsional yang memungkinkan sebuah organisasi untuk mencapaitujuan

b. Menurut Mulyadi (2001:40), Manajemen strategi adalah suatu proses yang 
digunakan oleh manajer dan karyawan untuk merumuskan dan mengimplementasikanstrategi dalam penyediaan costumer value terbaik untuk mewujudkan visi organisasi.

Berdasarkan beberapa pendapat tersebut, dapat disimpulkan bahwa manajemen strategi adalah seni dan ilmu untuk formulasi, implementasi dan evaluasi keputusan-keputusan yang bersifat lintas fungsional, yang digunakan sebagai panduan tindakan bagi fungsi SDM, pemasaran keuangan, produksi, dan lain-lain agar organisasi dapat mencapai tujuannya.

\section{Tahapan - Tahapan Manajemen Strategi}

David (2011:6) menjelaskan bahwa proses manajemen strategis terdiri dari tiga tahapan, yaitu :

\section{Perumusan Strategi (Strategy Formulation)}

Perumusan strategi adalah tahap awal pada manajemen strategi, yang mencakup mengembangkan visi dan misi, mengidentifikasi peluang eksternal organisasi dan ancaman, menentukan kekuatan dan kelemahan internal, menetapkan tujuan jangka panjang, menghasilkan strategi alternatif, dan memilih strategi tertentu untuk mencapai tujuan.

\section{Implementasi Strategi (Strategy Implemented)}

Pada tahap ini dilakukan pengembangan strategi pendukung budaya, merencanakan struktur organisasi yang efektif, mengatur ulang usaha pemasaran yang dilakukan, mempersiapkan budget, mengembangkan dan utilisasi sistem informasi serta menghubungkan kompensasi karyawan terhadap kinerja organisasi.

\section{Evaluasi Strategi (StrategyEvaluation)}

Evaluasi strategi adalah tahap akhir dalam manajemen strategis. Manajer sangat membutuhkan untuk tahu kapan strategi tertentu tidak bekerja dengan baik; Evaluasi strategi adalah alat utama untuk memperoleh informasi ini.

Strategi pemasaran didasarkan atas 5 (lima) konsep strategi sebagai berikut :

\section{a. Segmentasi Pasar}


Tiap pasar terdiri dari bermacam-macam pembeli yang mempunyai kebutuhan dan kebiasaan yang berbeda. Perusahaan tidak mungkin dapat memenuhi kebutuhan semua pembeli. Karena itu, perusahaan harus mengelompokkan pasar yang bersifat heterogen tersebut kedalam satuansatuan pasar yang bersifat homogen.

\section{b. Penentuan Posisi Pasar}

Perusahaan tidak mungkin dapat menguasai pasar secara keseluruhan, maka prinsip strategi pemasaran yang kedua adalah menentukan posisi pasar yang akan memberikan kesempatan maksimum kepada perusahaan untuk mendapatkan kedudukan yang kuat. Dengan kata lain perusahaan harus memilih segmen pasar yang akan menghasilkan penjualan dan laba paling besar.

\section{c. Strategi Memasuki Pasar}

Dalam memasuki segmen pasar yang dituju, perusahaan dapat menempuh beberapa cara antara kita membeli perusahaan lain, berkembang sendiri, dan mengadakan kerja sama dengan perusahaan lain.

\section{d. Strategi MarketingMix}

Strategi Marketing Mix adalah kumpulan variabel-variabel yang dapat dipergunakan perusahaan untuk memepengaruhi tanggapan konsumen. Variabel-variabel yang dapat mempengaruhi pembeli adalah yang disebut 7P (product, Price, Place, Promotion, Participant, Prosess, dan People Physical evidence).

\section{e. Strategi PenentuanWaktu}

Penentuan saat yang tepat dalam memasarkan barang merupakan hal yang perlu diperhatikan. Meskipun perusahaan melihat adanya kesempatan baik menetapkan objektif dan menyusun strategy pemasaran, ini tidaklah berarti bahwa perusahaan dapat segera memulai kegiatan pemasaran. Perusahaan harus lebih dahulu melakukan persiapanpersiapan baik dibidang produksi maupun dibidang pemasaran, kemudian perusahan juga harus menentukan saat yang tepat bagi pelemparan barang dan jasa ke pasar. 


\section{KEKUATAN PERSAINGAN INDUSTRI}

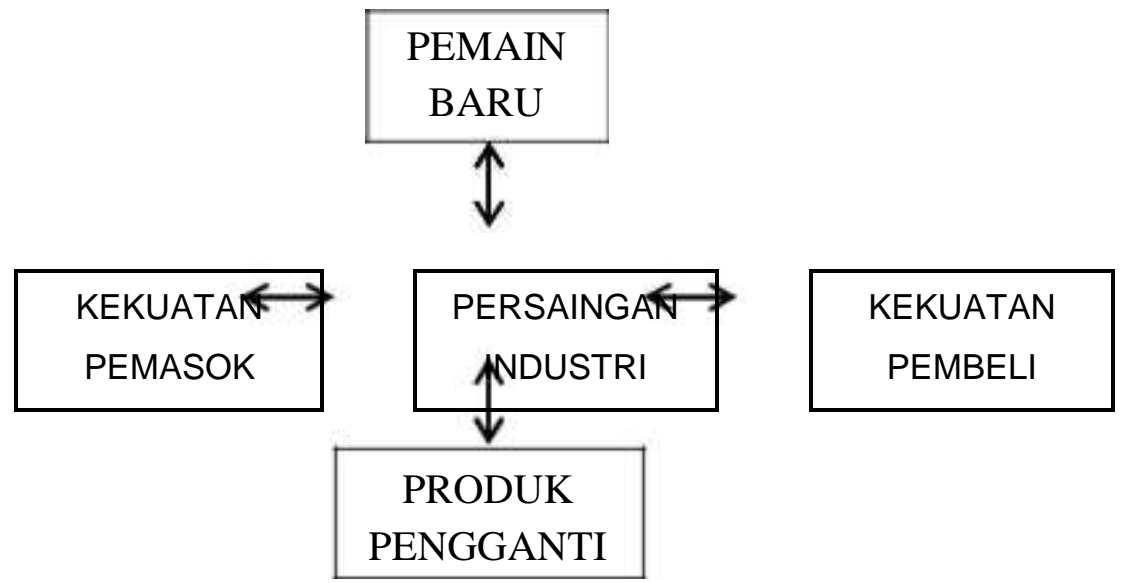

Gambar Kekuatan Persaingan Industri (Menurut Michael E. Porter)

\section{Persaingan Industri}

Ini merupakan salah satu tantangan dalam suatu industri dimana banyak persaingan dari industri - industri untuk tetap bisa bertahan di pasar.

\section{Pemain baru}

Ini merupakan salah satu tantangan terberat dalam suatu industry untukselalu meningkatkan kualitas dan pelayanan prima agar bisa bersaing dengan pemain baru dalam duniaindustry

\section{Kekuatan Pemasok}

Kekuatan pemasok merupakan factor penting dalam kelancaran suatu industry untuk dapat memasok bahan baku yang dibutuhkan industry tersebut.

\section{Kekuatan Pembeli}

Kekuatan pembeli merupakan hal yang sangat penting karena pembeli 
adalah konsumen yang akan menggunakan produk atau jasa yang ditawarkan oleh suatu industry.

\section{ProdukPengganti}

Produk pengganti merupakan salah satu bentuk persaingan industry, dimana ada industry lain yang menawarkan produk pengganti sebagai alternative dari produk lain yang diproduksi oleh suatu industry.

\section{E. Metodologi Penelitian}

Obyek Penelitian adalah Penerapan Promosi Strategi Pemasaran terhadap perkembangan Usaha pada PT JM Mutu Utama yg berlokasi di Central Business District, BSD City, Bidex Blok I No. 7-8 Tangerang Selatan 15310 Banten Indonesia

Salah satu pendekatan yang dapat dipergunakan sebagai instrumen dalam pemilihan strategi dasar adalah melalui analisis SWOT

\begin{tabular}{ll|l} 
& \multicolumn{2}{c}{ PELUANG } \\
KELEMAHAN & Kuadran 1 \\
\cline { 2 - 3 } & & \\
Kuadran 4 & KeKUATAN \\
ANCAMAN & Kuadran 2
\end{tabular}

\section{Gambar 1 : Diagram SWOT}

\section{Kuadran I :}

Ini merupakan situasi yang menguntungkan. Perusahaan tersebut memiliki peluang dan kekuatan sehingga dapat memanfaatkan peluang yang ada. Strategi yang diterapkan dalam kondisi ini adalah mendukung kebijakan pertumbuhan yang agresif. 


\section{Kuadran II :}

Meskipun menghadapi berbagai ancaman, perusahaan ini masih memiliki kekuatan dari segi internal. Strategi yang harus diterapkan adalah menggunakan kekuatan untuk memanfaatkan peluang jangka panjang dengan cara strategi diversifikasi (produk/pasar).

\section{Kuadran III :}

Perusahaan menghadapi peluang pasar yang sangat besar, tetapi di lain pihak menghadapi beberapa kendala/kelemahan internal. Fokus strategi ini yaitumeminimalkan masalah internal perusahaan sehingga dapat merebut pasar yang lebih baik (turnaround).

\section{Kuadran IV :}

Ini merupakan situasi yang sangat tidak menguntungkan, perusahaan tersebut menghadapi berbagai ancaman dan kelemahan internal. Fokus strategi yaitu melakukan tindakan penyelamatan agar terlepas dari kerugian yang lebih besar (defensive).

\section{F. Hasil dan Pembahasan}

\section{Matriks Analisis Faktor Strategis Eksternal}

Tabel 2 Faktor-Faktor Strategis Eksternal (Eksternal Strategic Factors Analysi Summary/EFAS)

\begin{tabular}{|l|cc|c|l|}
\hline \multicolumn{1}{|c|}{$\begin{array}{c}\text { FAKTOR-FAKTOR STRATEGIS } \\
\text { EKSTERNAL }\end{array}$} & BOBOT & RATING & $\begin{array}{c}\text { (BOBOT X } \\
\text { RATING) }\end{array}$ & KOMENTAR \\
\hline PELUANG & 0,20 & 4 & 0,80 & Akuisisi \\
\hline Integrasi ekonomi eropa & 0,15 & 4 & 0,60 & Kualitas \\
Perubahan struktur demografi & 0,15 & 4 & 0,60 & Maytag \\
Pembangunan ekonomi di Asia & 0,20 & 3 & 0,60 & Keberadaan \\
Terbukanya eropa timur & 0,10 & 3 & 0,30 & Perlu hati - \\
Kecendrungan superstores & 0,02 & 2 &
\end{tabular}


Manajemen Pemasaran ISSN No. (PRINT) 2598-0823, (ONLINE) 2598-2893

\begin{tabular}{|c|c|c|c|c|}
\hline Meningkatkan persaingan & 0,05 & 2 & 0,10 & $\begin{array}{l}\text { hati, perlu } \\
\text { tantangan }\end{array}$ \\
\hline Whirpool dan Electrolux menjadi global & 0,05 & 2 & 0,10 & $\begin{array}{l}\text { baru, Perlu } \\
\text { di }\end{array}$ \\
\hline Munculnya teknologi baru & 0,05 & 1 & 0,05 & perhatikan \\
\hline Perusahaan Jepang & 0,03 & 1 & 0,03 & \\
\hline Total & 1,00 & & 3,22 & \\
\hline
\end{tabular}

\section{Matriks Analisis Faktor Strategis Internal}

Tabel 3 Faktor-Faktor Strategis Internal (Internal Strategic Factors Analysis Summary/IFAS)

\begin{tabular}{|c|c|c|c|c|}
\hline $\begin{array}{c}\text { FAKTOR-FAKTOR STRATEGIS } \\
\text { INTERNAL } \\
\end{array}$ & BOBOT & RATING & $\begin{array}{l}\text { (BOBOT X } \\
\text { RATING) }\end{array}$ & KOMENTAR \\
\hline \multicolumn{5}{|l|}{ KEKUATAN } \\
\hline Budaya kualitas maytag & 0,15 & 4 & 0,60 & $\begin{array}{l}\text { Kualitas kunci } \\
\text { sukses }\end{array}$ \\
\hline Pengalaman top manajer & 0,15 & 4 & 0,60 & $\begin{array}{l}\text { Mengetahui } \\
\text { produk }\end{array}$ \\
\hline Intergrasi vertical & 0,10 & 4 & 0,40 & Hubungan baik \\
\hline \multirow{2}{*}{$\begin{array}{l}\text { Hubungan yang baik dengan SDM } \\
\text { Memiliki orientasi internasional }\end{array}$} & 0,05 & 3 & 0,15 & $\begin{array}{l}\text { Baik tapi } \\
\text { cenderung }\end{array}$ \\
\hline & 0,15 & 3 & 0,45 & $\begin{array}{l}\text { Memiliki reputasi } \\
\text { baik }\end{array}$ \\
\hline \multicolumn{5}{|l|}{ KELEMAHAN } \\
\hline Proses produksi (R\&D) & 0,05 & 2 & 0,10 & $\begin{array}{l}\text { Lambat untuk } \\
\text { produk baru }\end{array}$ \\
\hline Saluran distribusi & 0,05 & 2 & 0,10 & $\begin{array}{l}\text { Ancaman } \\
\text { superstore }\end{array}$ \\
\hline $\begin{array}{l}\text { Dukungan kondisi keuangan yang } \\
\text { kurang begitu baik }\end{array}$ & 0,15 & 1 & 0,30 & Tingginya Hutang \\
\hline Posisi global sangat kurang & 0,10 & 1 & 0,10 & $\begin{array}{l}\text { Lemah diluar UK } \\
\text { dan Australia }\end{array}$ \\
\hline Fasilitas manufaktur & 0,05 & 1 & 0,05 & $\begin{array}{l}\text { Perlu investasi } \\
\text { sekarang }\end{array}$ \\
\hline Total & 1,00 & & 2,85 & \\
\hline
\end{tabular}




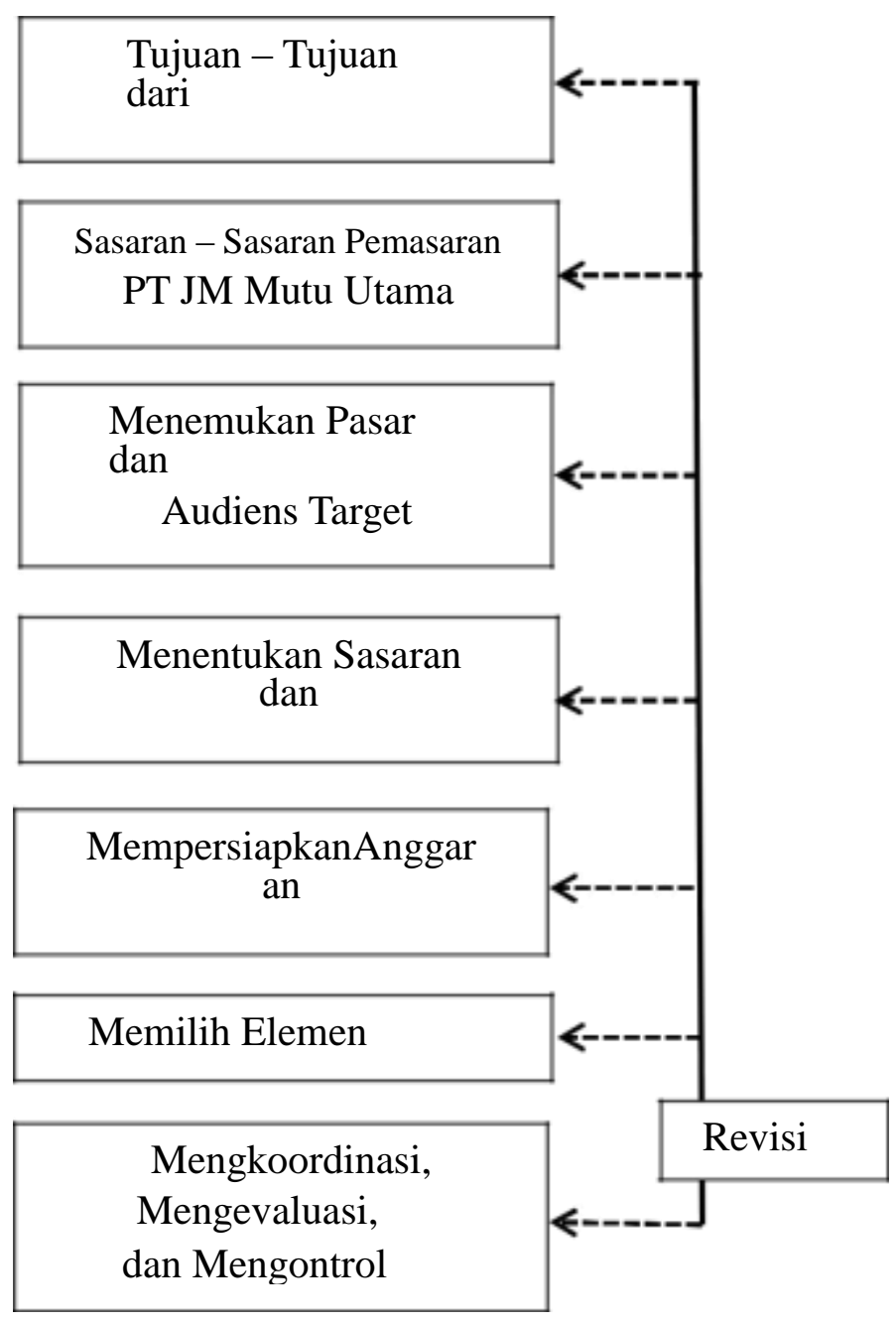

\section{Gambar Rangkaian Keputusan Promosi di PT JM Mutu Utama}

\section{ANALISIS KEKUATAN PT JM MUTUUTAMA}

\section{Harga Produk yangkompetitif}

Harga yang ditawarkan oleh PT JM Mutu Utama sangat kompetitif sehingga memberikan kekuatan bai perusahaan untuk mampu bersaing dalam hal penawaran harga kepada konsumen, khususnya melalui harga yang begitu kompetitif mka konsumen akan lebih tertaik untuk membeli produk di PT JM Mutu Utama.

\section{Mempertahankan KualitasProduk}

PT JM Mutu tama sangat memperhatikan kualitas produk yang 
dihasilkan oleh perusahaan. Sehingga adanya produk yang senantiasa unggul maka konsumen akan tetap menggunakan produk dari PT JM Mutu Utama. Tidak hanya itu, semua produk telah tersertifikasi dengan ISO 9001. Hal ini memberikan kekuatan bagi perusahaan dalam menjaga kualitas produk yang sudah terkenal di pasaran.

\section{Bahan Baku}

Dengan bahan baku yang melimpah serta pasokan supplai bahan baku yang selalu tepat waktu, akan menjadikan kekuatan bagi perusahaan untuk memproduksi tepat waktu sehingga konsumen bisa mendapatkan produk dengan mudah.

\section{SDMBerkualitas}

PT JM Mutu Utama memiliki kualitas SDM yang unggul. Karyawan PT JM Mutu Utama kebanyakan lulusan S1 baik dalam negeri maupun luar negeri dan banyak yang melanjutkan ke jenjang S2 untuk meningkatkan kualitas SDMnya.

\section{Alat dan mesin tekhnologitinggi}

Alat dan mesin yang digunakan oleh PT JM Mutu Utama memiliki teknologo yang tinggi sehingga dapat membuat kegiatan operasional dan kualitas barang menjadi efektif dan efisien, sehingga hal ini dapat menjadi kekuatan bagi kelangsungan produksi dam bisa meningkatkan volume penjualan.

\section{G. Kesimpulan}

1. Tingkat pertumbuhan volume penjualan produk - produk PT. JM Mutu Utama sangat bergantung dengan peran dari divisi pemasaran, dimana divisi pemasaran menentukan kesuksesan atau kebangkrutan perusahaan itu sendiri. Dan ini melatarbelakangi lahirnya strategi bauran pemasaran yang memungkinkan strategi produk, strategi harga, strategi promosi secara integrative

2. Berdasarkan analisi SWOT, posisi perusahaan terletak pada kuadran I. Hal ini menjelaskan bahwa PT JM Mutu Utama memiliki peluang lingkungan eksternal sebesar 2,70 dan kekuatan internal 3,45, maka 
Manajemen Pemasaran ISSN No. (PRINT) 2598-0823, (ONLINE) 2598-2893

strategi yang sesuai untuk dilakukan adalah strategi agresif atau perluasan untuk memaksimalkan kekuatan internal dan eksternal, contohnya seperti pengembangan pasar, pengembangan produk dan inovasi

\section{H. Daftar Pustaka}

1. Carls, Daniel \& Gates, Roger. 2001. Riset Pemasaran Kontemporer. Jakarta: Salemba Empat.

2. David, W Cravens. 1999. Pemasaran Strategi (Terjemahan). Jakarta: Erlangga

3. Fandy, Tjiptono. 2000. Strategi Pemasaran. Yogyakarta: Andi

4. Glaser, Ralph. 1968. Planned Marketing Policy for Business Growth. London: Pan Books Ltd.

5. Glueck, F. William \& Jauch, R. Lawrence. Business Policy and Strategic Management. Singapore: McGraw Hill.

6. Jhingan, ML. 2001. Ekonomi Pembangunan dan Perencanaan. Jakarta: Rajawali Press

7. Kotler, Philip \& Amstrong, Gary. 2003. Prinsip - Prinsip Pemasaran. Jakarta: Erlangga

8. Kotler, Philip \& Amstrong, Gary. 2007. Manajemen Pemasaran. Jakarta: Indeks.

9. Lamb, Hair \& Daniel, Mc. 2001. Manajemen Pemasaran Analisis, Perencanaan, Implementasi dan Pengendalian. Jakarta: Salemba Empat.

10. Lamb, Hair \& Daniel, Mc. 2001. Pemasara. Jakarta: Erlangga.

11. Luck, David J \& Ferrel O.C.1982. Marketing Strategy and Plans. New Delhi: Prentice Hall of India Private Limited.

12. Lincolin, Arsyad. 1999. Ekonomi Pembangunan. Yogyakarta: STIE YKPN. 
13. McCharty, E. Jerome \& Perreault, William. 1991. Essentials of Marketing. Boston: E. Jerome McCharty \& Associates Inc.

14. Pride, William M \& Ferrel, O.C. 1999. Marketing Concept and Strategy. Boston: Hougton Mifflin Company.

15. Rangkuti, Freddy. 2009. Analiisi SWOT Teknik Membedah Kasus Bisnis. Jakarta: PT Gramedia Pustaka Utama..

16. Stanton, J William \& Lamarto, Yohanes. 1984. Prinsip Pemasaran. Jakarta: Erlangga.

17. Suryadi, Prowiro Sentono. 2001. Manajemen Operasi (Analisis Studi Khusus)

18. Swasta, Basu. 2000. Azas - Azas Marketing. Yogyakarta: Liberty.

19. Swasta, Basu \& Irawan. 2002, Manajemen Pemasaran Modern. Yogyakarta: Liberty

20. Swasta, Basu \& Sukotjo, Ibnu, Pengantar Bisnis. 2002, Manajemen Pemasaran Yogyakarta: Liberty.

21. Zeithmal, V.A dan Bitner, M.J. 2000. Service Marketing, Intergrating Customer Fokus Across The Firm (Secondt EdotionO Internastional. Choi Minho. Singapore: Prectice Hall. 